Open Access

\title{
Development and implementation of ISAR, a new synthesis platform for radiopharmaceutical production
}

Christopher Frank ${ }^{1 *}$, Georg Winter ${ }^{1}$, Fredrik Rensei ${ }^{2}$, Victor Samper ${ }^{3}$, Allen F. Brooks ${ }^{4}$, Brian G. Hockley ${ }^{4}$, Bradford D. Henderson ${ }^{4}$, Christian Rensch ${ }^{3}$ and Peter J. H. Scott ${ }^{4^{*}}$ (i)

* Correspondence: Christopher Frank@ge.com; pjhscott@med. umich.edu

${ }^{1}$ GE Healthcare,

Oskar-Schlemmer-Str. 11, 80807 Munich, Germany

${ }^{4}$ Department of Radiology, University of Michigan, 2276 Medical Science Bldg I, SPC 5610, Ann Arbor, MI 48109, USA Full list of author information is available at the end of the article

\section{Springer Open}

\begin{abstract}
Background: PET radiopharmaceutical development and the implementation of a production method on a synthesis module is a complex and time-intensive task since new synthesis methods must be adapted to the confines of the synthesis platform in use. Commonly utilized single fluid bus architectures put multiple constraints on synthesis planning and execution, while conventional microfluidic solutions are limited by compatibility at the macro-to-micro interface. In this work we introduce the ISAR synthesis platform and custom-tailored fluid paths leveraging up to 70 individually addressable valves on a chip-based consumable. The ISAR synthesis platform replaces traditional stopcock valve manifolds with a fluidic chip that integrates all fluid paths (tubing) and valves into one consumable and enables channel routing without the single fluid bus constraint. ISAR can scale between the macro- $(10 \mathrm{~mL})$, meso- $(0.5 \mathrm{~mL})$ and micro$(\leq 0.05 \mathrm{~mL})$ domain seamlessly, addressing the macro-to-micro interface challenge and enabling custom tailored fluid circuits for a given application. In this paper we demonstrate proof-of-concept by validating a single chip design to address the challenge of synthesizing multiple batches of $\left[{ }^{13} \mathrm{~N} \mathrm{NH}_{3}\right.$ for clinical use throughout the workday.

Results: ISAR was installed at an academic PET Center and used to manufacture $\left[{ }^{13} \mathrm{~N}^{\mathrm{N}} \mathrm{NH}_{3}\right.$ in $>96 \%$ radiochemical yield. Up to 9 batches were manufactured with a single consumable chip having parallel paths without the need to open the hot-cell. Quality control testing confirmed the ISAR-based $\left[{ }^{13} \mathrm{~N} \mathrm{NH}_{3}\right.$ met existing clinical release specifications, and utility was demonstrated by imaging a rodent with $\left[{ }^{13} \mathrm{~N}_{\mathrm{NH}_{3}}\right.$ produced on ISAR.

Conclusions: ISAR represents a new paradigm in radiopharmaceutical production. Through a new system architecture, ISAR integrates the principles of microfluidics with the standard volumes and consumables established in PET Centers all over the world. Proof-of-concept has been demonstrated through validation of a chip design for the synthesis of $\left[{ }^{13} \mathrm{~N}^{-\mathrm{NH}_{3}}\right.$ suitable for clinical use.
\end{abstract}

Keywords: Microfluidics, Lab on a chip, Automation, $\left[{ }^{13} \mathrm{~N}\right]$ ammonia, Myocardial perfusion imaging

\section{Background}

Positron emission tomography (PET) is a functional molecular imaging technique that utilizes bioactive molecules labeled with a positron-emitting radionuclide (radiopharmaceuticals) to non-invasively quantify physiological and biochemical processes (for a

(c) The Author(s). 2019 Open Access This article is distributed under the terms of the Creative Commons Attribution 4.0 International License (http://creativecommons.org/licenses/by/4.0/), which permits unrestricted use, distribution, and reproduction in any medium, provided you give appropriate credit to the original author(s) and the source, provide a link to the Creative Commons license, and indicate if changes were made. 
general review of PET imaging, see: Ametamey et al. 2008). During the PET scan, subjects receive a radiopharmaceutical dose and the scanner detects pairs of coincident $511 \mathrm{keV}$ gamma photons emitted indirectly by the PET radionuclide. Data is then reconstructed to generate the PET image. Several PET radiopharmaceuticals have been approved for clinical use (Vavere and Scott 2017) and, reflecting this, millions of PET scans occur worldwide every year (PET Imaging Market Summary Report 2018). The short half-life of PET radionuclides (typically minutes - hours) mandates that radiopharmaceuticals are manufactured at a radiopharmacy facility that is in close proximity to the clinical PET scanner(s) on a daily basis. The synthesis and delivery of PET radiopharmaceuticals for clinical use present some unique challenges including the need for a manufacturing process that is rapid, reliable, automated and affordable so as to be compatible with short-lived PET radionuclides, current Good Manufacturing Practice (cGMP), radiation safety and healthcare economics. To accomplish daily dose production, radiopharmaceuticals are typically manufactured using automated synthesis modules housed in lead-lined hot-cells (Thompson and Scott 2019).

Many traditional radiochemistry synthesis modules use a single fluid bus architecture in conjunction with stopcock valve manifold(s), in which every fluid runs through parts of the central pathway (Fig. 1). They are cassette-based systems that require a varying degree of customer assembly, optimized for a single radionuclide and designed to produce one or a few large batches (e.g. tens to hundreds of GBq) of a given PET radiopharmaceutical for routine clinical use. For example, because $\left[{ }^{18} \mathrm{~F}\right]$ fludeoxyglucose ( $\left.\left[{ }^{18} \mathrm{~F}\right] \mathrm{FDG}\right)$ is the most common PET radiopharmaceutical in clinical use and the halflife of ${ }^{18} \mathrm{~F}\left(\mathrm{t}_{1 / 2}=110 \mathrm{~min}\right)$ is compatible with centralized production, many synthesis modules have been designed for the express purpose of manufacturing $\left[{ }^{18} \mathrm{~F}\right] \mathrm{FDG}$ (Ametamey et al. 2008; Yu 2006).

Therefore, the implementation of other syntheses requires subsequent adaptations of the $\left[{ }^{18} \mathrm{~F}\right] \mathrm{FDG}$ baseline architecture (Yu 2006). However, the synthesis and utilization of all PET radiopharmaceuticals does not necessarily fit this manufacturing paradigm. For example, in developing markets there is a tendency to synthesize single patient doses as needed, rather than large multidose batches. Alternatively, the use of short-lived PET radionuclides (e.g. ${ }^{15} \mathrm{O}\left(\mathrm{t}_{1 / 2}=2 \mathrm{~min}\right),{ }^{13} \mathrm{~N}\left(\mathrm{t}_{1 / 2}=10 \mathrm{~min}\right),{ }^{11} \mathrm{C}\left(\mathrm{t}_{1 / 2}=20 \mathrm{~min}\right),{ }^{68} \mathrm{Ga}$ $\left.\left(\mathrm{t}_{1 / 2}=68 \mathrm{~min}\right)\right)$ to label other radiopharmaceuticals necessitates de-centralized production of different radiopharmaceuticals in batches suitable for 1-2 patients at a time on

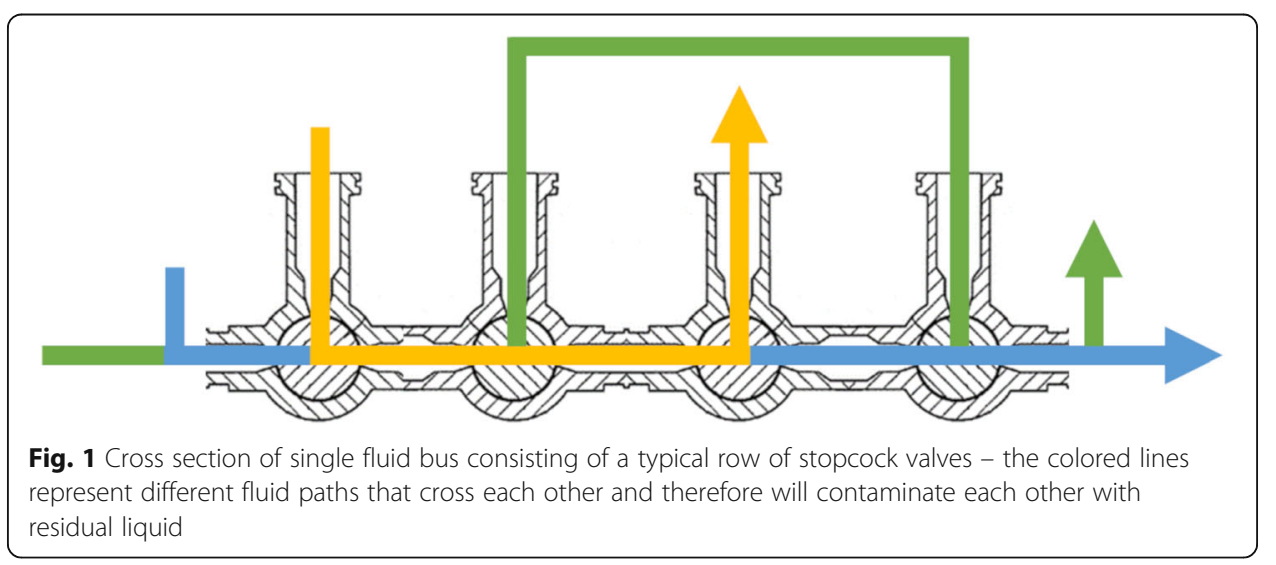


a continuous basis throughout the day (Wang et al. 2010; Elsinga 2012; Keng et al. 2012a; Rensch et al. 2013). Production of several batches on a single fluid path architecture relies on replacing consumables multiple times per day, or rinsing procedures between production steps (to avoid cross contamination), which creates further expense and/or complexity in validation of these cleaning processes (Haka et al. 2017).

There is a need for a more flexible radiopharmaceutical synthesis platform that is compatible with different levels of radioactivity (single dose-on-demand production or multidose batches) as well as a variety of radionuclides and/or radiopharmaceuticals, and which can fit into the space confines of a typical radiopharmacy laboratory with only one or two hot-cells. Ideally, it does not rely on cleaning procedures and aligns with the state-of-the art approach of single-use disposables. To date, efforts in this direction have focused on development of microfluidic approaches for radiopharmaceutical manufacturing (Amaraesekera et al. 2013; Audrain 2007; Awasthi et al. 2014; Bejot et al. 2010; Bouvet et al. 2011; Bouvet et al. 2012; Bouvet and Wuest 2013; Chen et al. 2014; Collier et al. 2010, 2017; De Leonardis et al. 2010, 2011; Gaja et al. 2012; Gillies et al. 2006; Lu and Pike 2007; Lu and Pike 2010; Elizarov 2009; Elizarov et al. 2010; Fortt and Gee 2013; Kealey et al. 2011; Keng et al. 2012b; Keng and van Dam 2015; Lee et al. 2005; Liow et al. 2005; Liu et al. 2011; Liu et al. 2013; Lu et al. 2004, 2009, 2010; Matesic et al. 2017; Miller 2009; Miller et al. 2010, 2011; Pascali et al. 2010, 2011, 2013; Pascali and Salvadori 2016; Rensch et al. 2012, 2013; Selivanova et al. 2012; Simms et al. 2012; Steel et al. 2007; Ungersboeck et al. 2011, 2012a, 2012b; Voccia et al. 2009; Wang et al. 2010; Wang et al. 2019; Wester et al. 2009; Wheeler et al. 2010; Yokell et al. 2012; Zeng et al. 2013), as well as purification/reformulation (Chao et al. 2017) and quality control (QC) testing (Ha et al. 2017; Taggart et al. 2016; Ly et al. 2018). While the benefits of microreactors for radiopharmaceutical synthesis have been well documented in this multitude of literature precedent, and they have been used to prepare radiopharmaceuticals for clinical use (Lebedev et al. 2013; Liang et al. 2014a, 2014b; Rensch et al. 2014), there are continuing challenges that have prevented them from commercialization and really transitioning into widespread use to date (Chiu et al. 2017). Notable exceptions in the PET space include ABTs BG75 (Awasthi et al. 2014) and the Advion Nanotek (Pascali et al. 2014), but both systems remain confined to only a small number of laboratories around the world as of 2019.

The reasons for the slow uptake of microfluidic systems within the PET community despite the well documented benefits are numerous and depend on the particular application objective, but from the perspective of a clinical end user, include: I) system cost (in our experience, some commercial microfluidic systems are almost double the cost of standard radiopharmaceutical synthesis modules), II) the lack of availability of affordable components due to dependence on chips, III) issues with the macro-to-micro interface, or general incompatibility between microfluidic volumes $(\leq 0.05 \mathrm{~mL})$ and the typical "large-scale" volumes used in cyclotrons and radiopharmaceutical dosing $(\geq$ $10 \mathrm{~mL}$ ), and IV) a lack of improvement over existing technology.

To address a number of these issues, in this report we introduce $\operatorname{ISAR}^{1}$ (Fig. 2) as well as the ISAR chip (Fig. 3), a readily available injection molded component that is entirely manufactured out of cyclic olefin copolymer (COC) and integrates all reaction

${ }^{1}$ ISAR is the name of the synthesis module and not an acronym. 


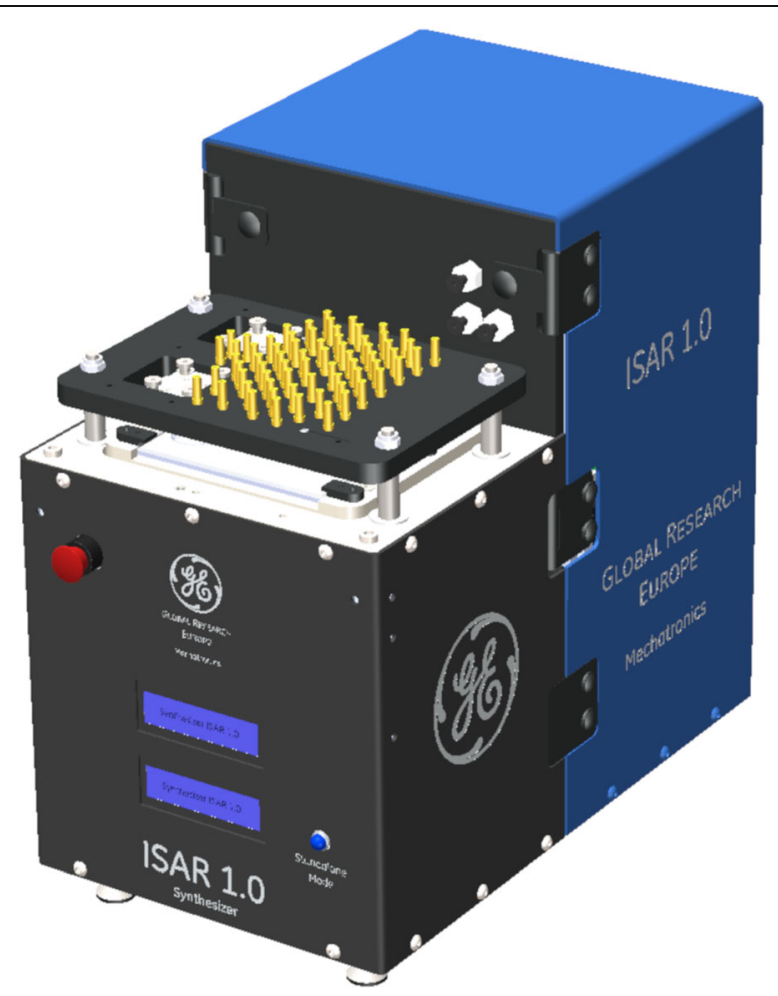

Fig. 2 ISAR unit ( $\mathrm{W} \times \mathrm{L} \times \mathrm{H} 20 \times 34 \times 34 \mathrm{~cm})$ with 70 luer connectors on top enabling the macro-tomicro interface between the fluidic chip and standard laboratory items used in the production of radiopharmaceuticals

vessels, fluid paths (tubing) and valves into one consumable, and enables direct pointto-point channel routing. This work reduces to practice the lab-on-chip concepts that GE have been developing in recent years (for example, see: Rensch et al. 2014, 2017, 2018). Such a concept is analogous to multi-layered printed circuit boards in electronics. This configuration eliminates a single fluid bus, thereby reducing challenges associated with

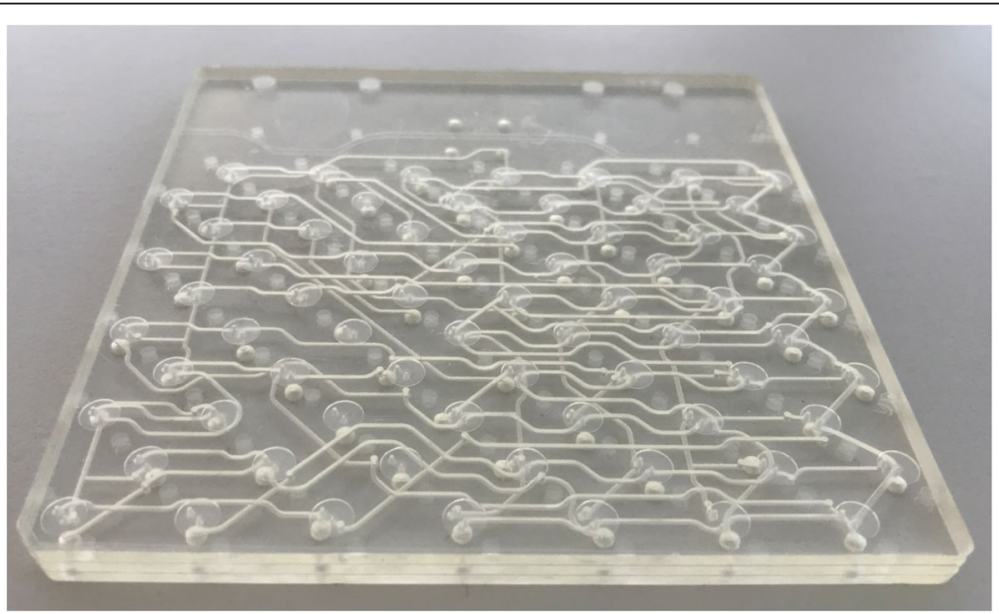

Fig. 3 ISAR chip (W $\times$ L $\times$ H 10,4 $\times 10,4 \times 0,6 \mathrm{~cm}$ ) with 70 on-chip membrane valves hosting multiple parallel fluid paths enabling point-to-point routing - the shown layout is designed for nine production runs of $\left[{ }^{13} \mathrm{~N}_{\mathrm{NH}}\right.$ 
cross-contamination and the need for complex cleaning validation (Haka et al. 2017). While the multi-layer fluid routing facilitates complex syntheses, the applicability to multiple independent productions has also been realized, and is the focus of this paper. The ISAR system offers both parallel fluidics (Frank et al. 2018) and independent fluidics (this work) (Fig. 4), potentially disruptive technologies that overcome the single fluid bus and associated challenges at the macro-to-micro interface by marrying standard volumes, techniques, and off-the-shelf components for radiopharmaceutical synthesis with the established benefits of a microreactor setup.

Preliminary proof-of-concept was recently shown through the on chip synthesis of two commonly used PET radiopharmaceuticals (Fig. 5). $\left[{ }^{18} \mathrm{~F}\right]$ FDG (1) was produced with an overall activity yield (AY) of $\sim 65 \%(>100 \mathrm{GBq})$ in less than $25 \mathrm{~min}$ and $\left[{ }^{68} \mathrm{Ga}\right]$ PSMA-HBED-CC (2) was manufactured in a dual run scenario (two separate runs from the same consumable) each resulting in $\sim 44 \%$ AY $(<11.5 \mathrm{~min}$ synthesis time) (Frank et al. 2018). On our development roadmap, these two steps confirmed I) fundamental technical feasibility of ISAR, process efficiencies competitive to state-ofthe-art routine $\left[{ }^{18} \mathrm{~F}\right]$ FDG production, II) reduced synthesis time, and III) capability of multi-run architectures for e.g. two ${ }^{68} \mathrm{Ga}$ syntheses from a single set of reagents. Following successful proof-of-concept demonstration, we next sought to install ISAR under real-life conditions at a busy PET center and compare performance with existing in-house standards for a challenging process. Concurrent with these efforts, we realized that parallel processing is also well suited for multi-run schemes of simple production processes, such as $\left[{ }^{13} \mathrm{~N}\right] \mathrm{NH}_{3}$ for myocardial perfusion imaging. We therefore selected synthesis of $\left[{ }^{13} \mathrm{~N}\right] \mathrm{NH}_{3}$ for high resolution myocardial perfusion imaging (MPI) with which to conduct the first field test of ISAR. Validation of the synthesis of $\left[{ }^{18} \mathrm{~F}\right]$ FDG and $\left[{ }^{68} \mathrm{Ga}\right]$ PSMA for clinical use are also ongoing and will be reported in due course.

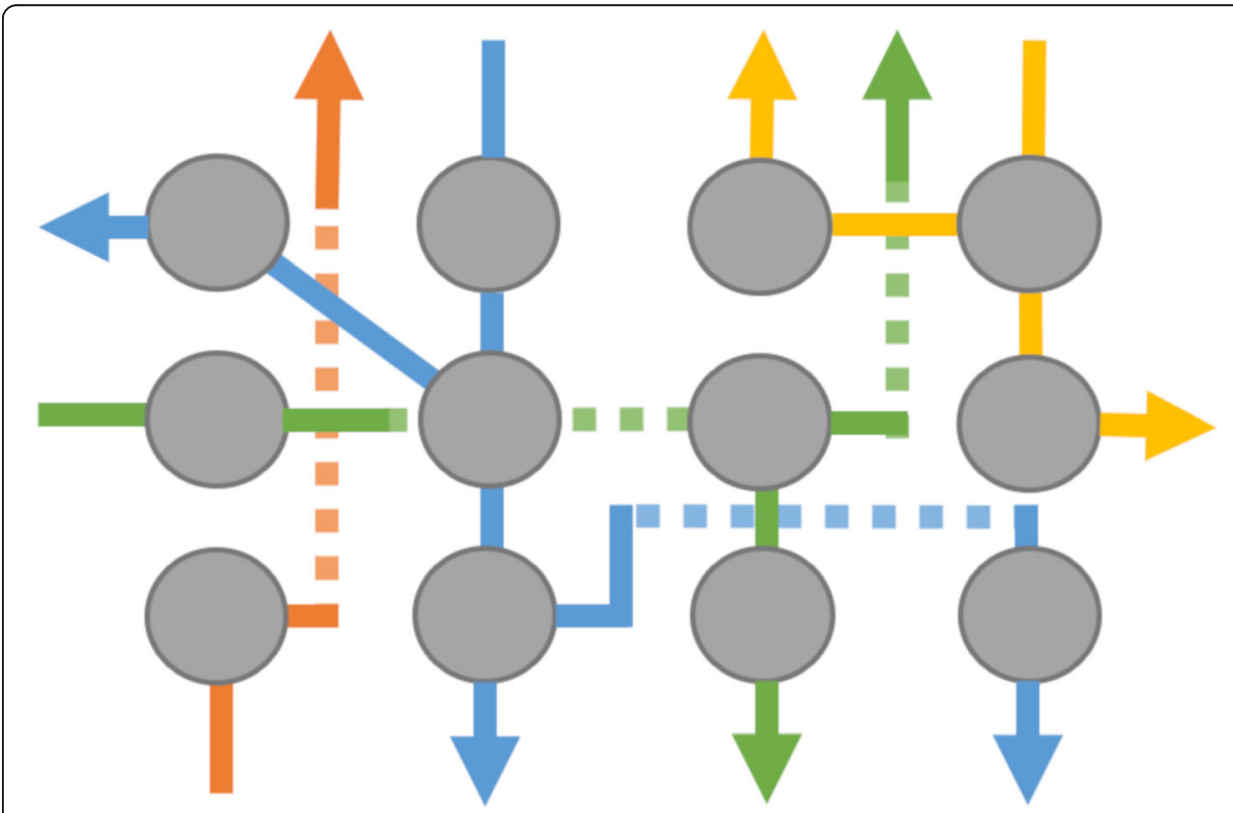

Fig. 4 Illustration of the parallel fluidic architecture running on both sides of the same layer (doted lines on the opposite side), thus enabling contamination free crossing of fluid paths 


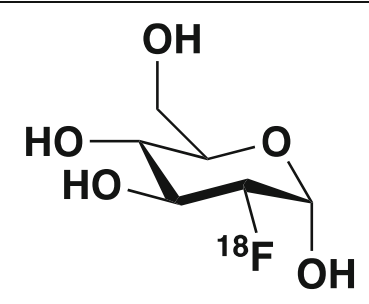<smiles></smiles>

$\left[{ }^{18} \mathrm{~F}\right] \mathrm{FDG}(1)$

$\left[{ }^{13} \mathrm{~N}\right] \mathrm{NH}_{3}(3)$

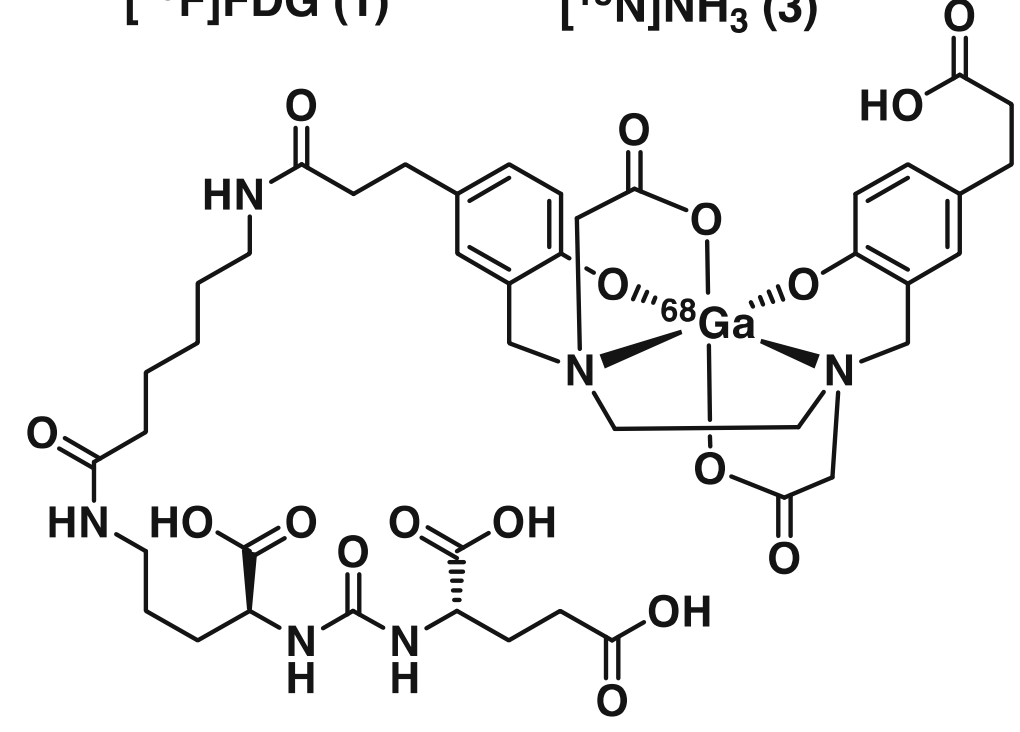

$\left[{ }^{68} \mathrm{Ga}\right]$ PSMA-HBED-CC (2)

Fig. 5 The different Isotopes used, and radiopharmaceuticals produced with ISAR so far - (1) $\left[{ }^{18}\right.$ F $]$ fludeoxyglucose; (2) $\left[{ }^{68} \mathrm{Ga}\right] \mathrm{Ga}-\mathrm{PSMA}-\mathrm{HBED}-\mathrm{CC} ;(3)\left[{ }^{13}{\mathrm{~N}] \mathrm{NH}_{3}}\right.$

Historically, assessments of myocardial perfusion are conducted with ${ }^{82} \mathrm{Rb}$ because the radionuclide is readily available from generators (Yoshinaga et al. 2010; Nakazato et al. 2013). However, owing to generator supply challenges and reduced imaging quality stemming from the relatively high positron energy of ${ }^{82} \mathrm{Rb}$, there is motivation to conduct high resolution myocardial perfusion imaging (MPI) with cyclotron-based $\left[{ }^{13} \mathrm{~N}\right] \mathrm{NH}_{3}$ instead (Murthy et al. 2016). The transition to MPI with $\left[{ }^{13} \mathrm{~N}\right] \mathrm{NH}_{3}$ presents significant production challenges to PET radiopharmaceutical manufacturers however. Specifically, the short half-life of ${ }^{13} \mathrm{~N}\left(\mathrm{t}_{1 / 2}=10 \mathrm{~min}\right)$ requires continuous production of high numbers of doses throughout the day to meet busy imaging schedules. For particularly short-lived radionuclides, the regulations allow quality control $(\mathrm{QC})$ testing to be conducted on an initial sub-batch of the radiopharmaceutical ( $<823>$ Positron Emission Tomography Drugs for Compounding, Investigational, and Research Uses, in USP 42-NF 37, 2018). Subsequent sub-batches can then be manufactured and sent directly to the imaging suite in a given period (usually $24 \mathrm{~h}$ ) without additional QC testing. Despite the convenient sub-batch allowance, the traditional Devarda's alloy method used for routine synthesis of $\left[{ }^{13} \mathrm{~N}^{-N_{3}}\right.$ at the University of Michigan PET Center requires new reagents and consumables for production of each sub-batch (Scott 2012). This has inherent costs, operational complexity (sub-batches need to be manufactured and purified from target impurities rapidly given the short half-life; high numbers of batches are required per day (1-2 per patient); space 
constraints limit how many batches can be set up in advance using a single hot-cell; $\left[{ }^{13} \mathrm{~N}\right] \mathrm{NH}_{3}$ production needs to fit into a busy workflow where multiple lots of multiple PET radiopharmaceuticals are already being prepared simultaneously), and undesirable radiation exposure to workers who have to replace spent consumables throughout the day that contain residual nitrogen-13 in spite of the short half-life. As such, we had a strong interest in being able to prepare multiple $5.6-7.4 \mathrm{GBq}$ sub-batches of $\left[{ }^{13} \mathrm{~N}\right] \mathrm{NH}_{3}$ with a single consumable so that, after purification and transport to the imaging suite, it is possible to draw both rest $(370 \mathrm{MBq})$ and stress $(740 \mathrm{MBq})$ doses $20 \mathrm{~min}$ apart from a single batch. Leveraging the parallel fluidic architecture of our new chips as well as the small dead volumes, in this paper we report installation of ISAR at the University of Michigan PET Center and use of the system to produce up to 9 doses of $\left[{ }^{13} \mathrm{~N}\right] \mathrm{NH}_{3}$ (Fig. 5 (3)) using a single consumable chip and set of reagents.

\section{Methods}

\section{Safety and hazard considerations}

Radioactivity and all hazardous chemicals were used by trained personnel under the supervision of Environmental Health and Safety and the Radiation Policy Committee at the University of Michigan.

\section{Chip Design and manufacturing}

The fluidic chip consumable integrates all reaction vessels, fluid paths and valves into one consumable and is a readily available injection molded component that is entirely manufactured out of cyclic olefin copolymer $(\mathrm{COC})$. This material offers excellent resistance against acids, bases, and solvents commonly used in the production of radiopharmaceuticals (e.g. acetonitrile and dimethyl sulfoxide). Three layers and a COC foil are joined in a bonding process without the use of any adhesives or binders, reducing material impurities and unwanted residuals (Fig. 6). To date over 1500 chips have been

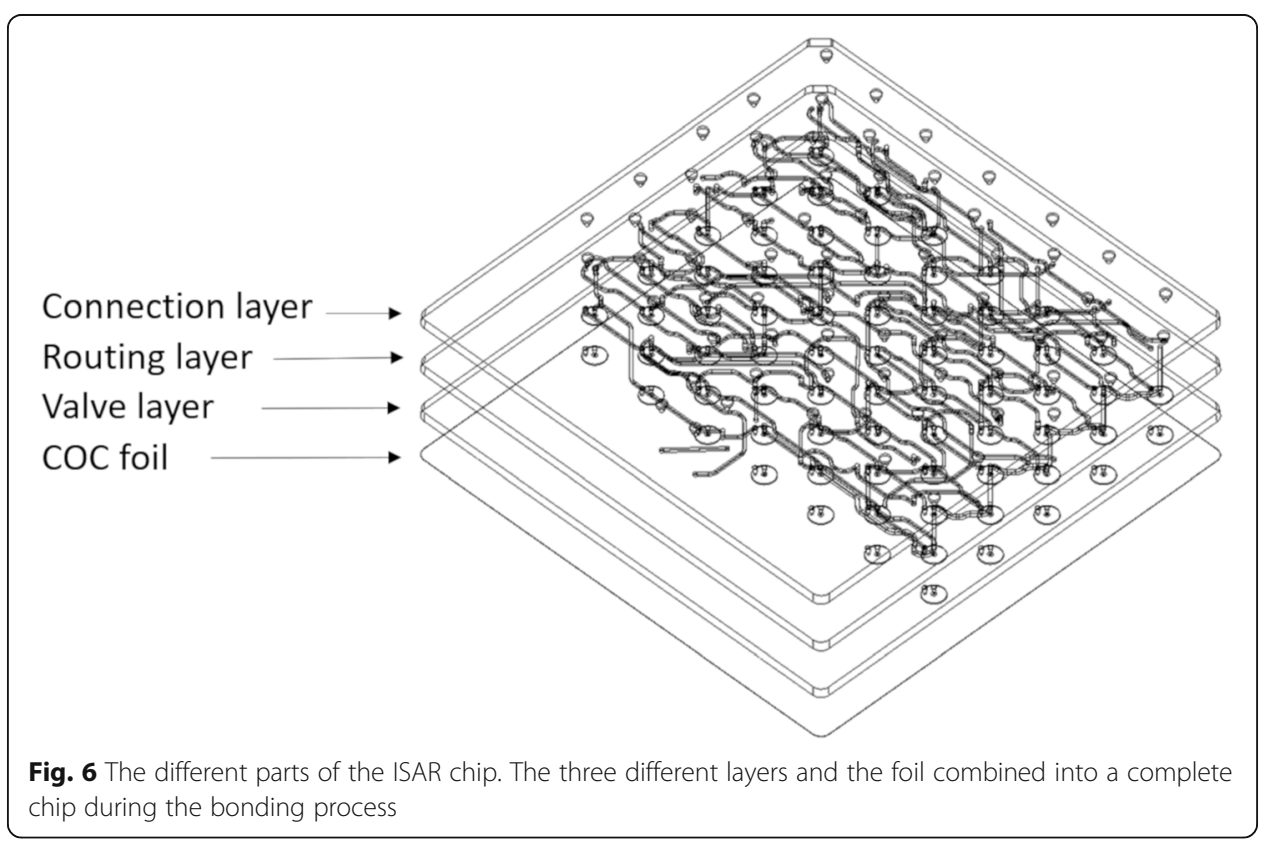


produced with a scrap rate below $1 \%$. Representative samples from each batch are checked under the microscope and we have not observed any wear in the manufacturing tools. Bond quality is currently conducted by visual inspection and destructive testing of samples.

The COC foil forms the valves together with the valve layer that contains 70 membrane valves. Those valves are connected through the routing layer towards reaction structures on the chip, thus replacing the majority of tubing utilized in a conventional consumable. At the same time, the available routing logic is increased by the high packing density of channels and structures on the chip. The valve array pattern is dictated by injection molding considerations and the connection points follow an equal distance distribution with two exceptions: two positioning pins and an additional area for further connection points between the two reaction chambers. The fluid paths are then designed to fit together with both patterns. The final chip dimensions are $104 \times 104 \times 6$ $\mathrm{mm}$ (with a $3 \mathrm{~mm} 45^{\circ}$ recess at one corner to help with correct orientation when used) and valve spacing is $10.3 \mathrm{~mm}$. Valves, as the critical structures, are specified to function after $>100$ actuation cycles and at 5 bar $(72.5 \mathrm{psi})$ over pressure. To test this, $>250$ valves were evaluated as shown in Table 1 .

Access to off-the-shelf components such as solid phase extraction (SPE) cartridges and fluid vials is maintained through 70 connection points on the connection layer, that can serve as in-and/or outlets. The valve and connection layers are standardized and injection molded parts. The routing layer can be manufactured by rapid prototyping (milling of a blank), or injection molding during commercialization ramp-up. These are reliable techniques for manufacturing microfluidic chips (Attia et al. 2009; Guckenberger et al. 2015), and have been successfully demonstrated for $\left[{ }^{18} \mathrm{~F}\right]$ FDG and $\left[{ }^{13} \mathrm{~N}\right] \mathrm{NH}_{3}$ ISAR chips. This enables manufacturing scalability from prototyping across low rate initial production to cost competitive mass production of chips. In addition, iterative process design is possible by making adaptive changes to the routing layer in the prototyping phase. It allows the production of custom-made chips in the scale of a small series (10 to 500 copies) at acceptable cost. If the number of chips required is high enough to justify it, the finalized design can then be transferred to injection molding (Fig. 7).

The routing logic contains different reaction structures and channels customized towards the process at hand. It can make use of two reaction chambers $(\sim 650 \mu \mathrm{L}$ each $)$ and a variety of different fluidic structures, designed for mixing, metering of volumes, and dilution. Everything can be either directly routed point-to-point (preventing cross contamination or the need for cleaning validation), in a row, or in a combination of both. External components such as standard SPE cartridges or vials can be routed according to the same principle across I/Os of the connection layer. The channel diameters can be selectively scaled from micro $(<50 \mu \mathrm{m})$ to macro $(>2 \mathrm{~mm})$ depending on the liquid volumes that need to be transferred and optimized (e.g. fluid volume, mass

Table 1 Valves Used in ISAR Chips

\begin{tabular}{llll}
\hline Entry & Test & Result & $\mathrm{n}$ \\
\hline 1 & $\mathrm{~N}_{2}(2$ bar) leakage & $<10 \mu \mathrm{L} / \mathrm{min}$ & $>250$ \\
2 & Valve functional after $>100$ cycles & Pass & $>250$ \\
\hline
\end{tabular}




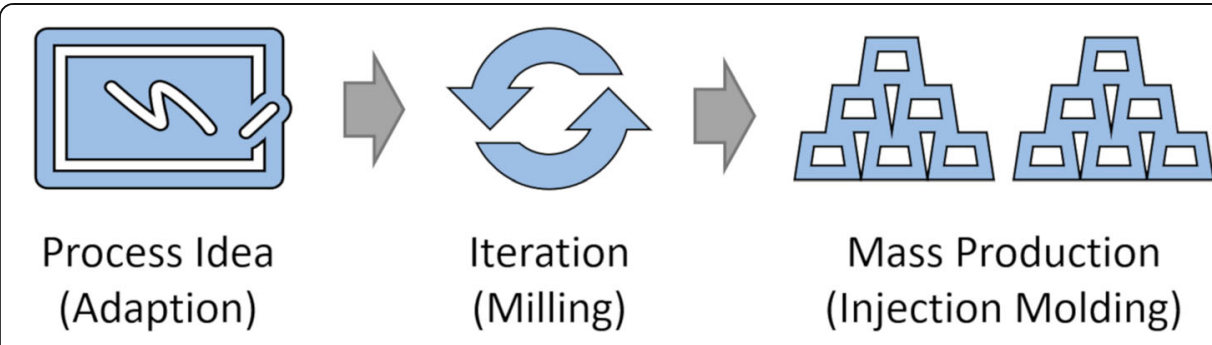

Fig. 7 Illustration of the chip design process. An existing chip layout is adopted to a new process or the layout is created from scratch. Iterations of the layout are fabricated by milling the layout into a blank routing layer, which later can be transferred to injection molding for mass production

transfer, heat transfer, fluid viscosity and/or residual dead volume). The developer can start with a sub-optimal design for first results and (re) iterate as required.

\section{ISAR hardware}

An ISAR unit is a compact, highly automated platform (Figs. 2 and 8), capable of producing various radiopharmaceuticals using consumable chips that integrate all reaction vessels, fluid paths (tubing) and valves into one consumable (Figs. 3, 6, 9 and 10). The

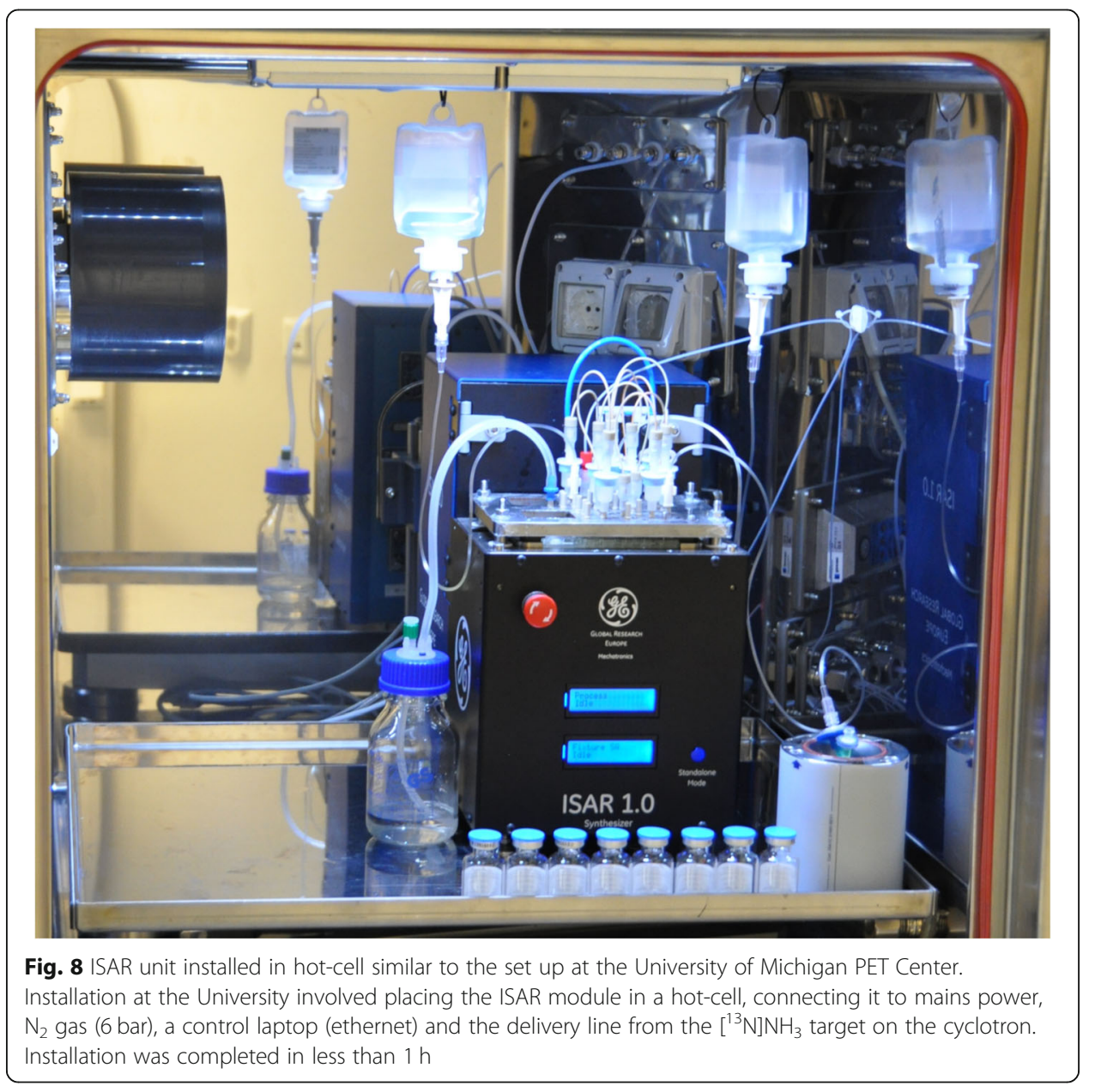




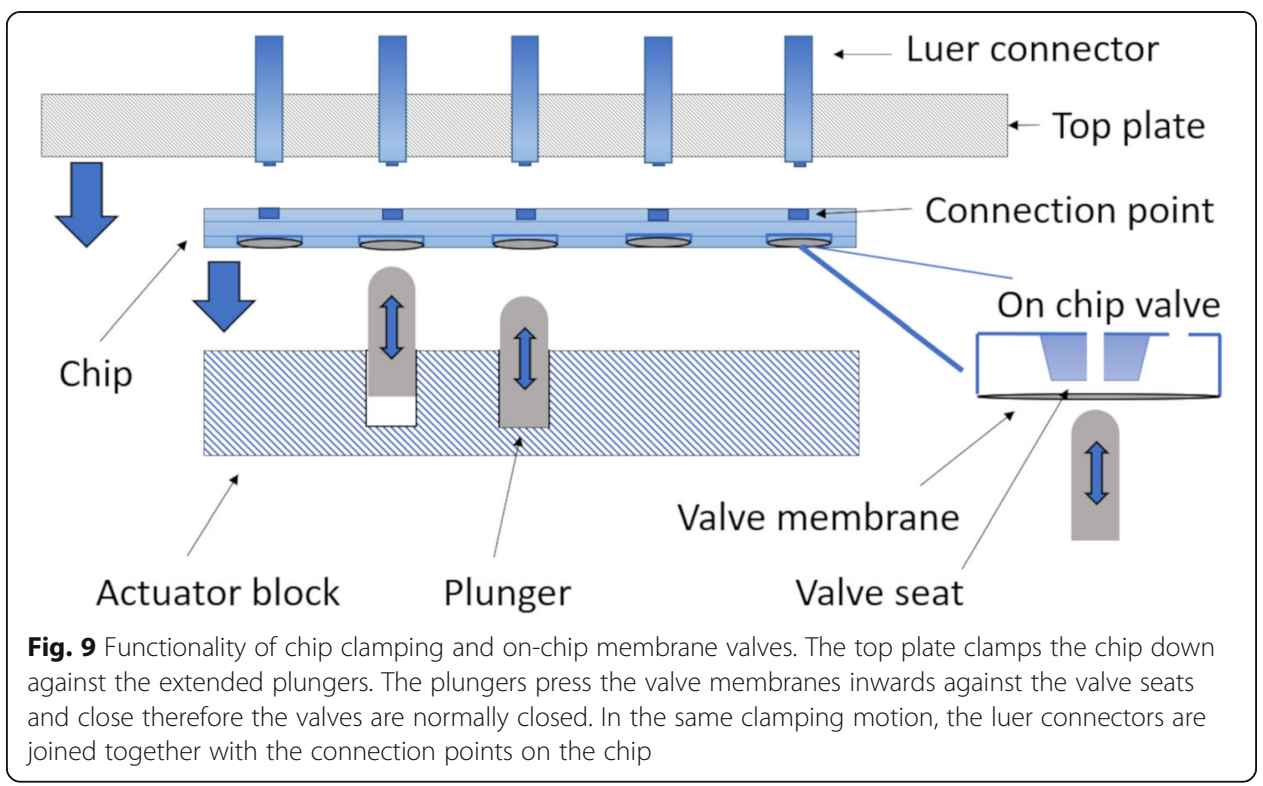

fluid paths are then designed to fit together with both patterns and with certain safety and design considerations based on experience in mind From the point of view of routing fluids, the core functionality of the system is based on an actuator block, which enables an individual binary on-chip valve control. The unit and consumable are brought together by clamping the chip down by the top plate against the actuator block, simultaneously connecting the chip to the luer connectors integrated in the top plate and putting the membrane valves in a normally closed position (Rensch et al. 2018). Each valve membrane is pressed against its corresponding on-chip valve seat by a respective electro-pneumatically actuated mechanical plunger (Fig. 9). The combination of electro-pneumatics and the membrane valves allows for a precise, real-time control of valves. Completion of each actuation is achieved within a reliable, defined time window with actuation times of $<10 \mathrm{~ms}$ (closed-open-closed cycle in $<30 \mathrm{~ms}$ ). This real-time valve switching capability is in marked contrast to traditional stopcock valve manifolds, which rely on rotational motion of valve drivers at actuation times often exceeding $1 \mathrm{~s}$.

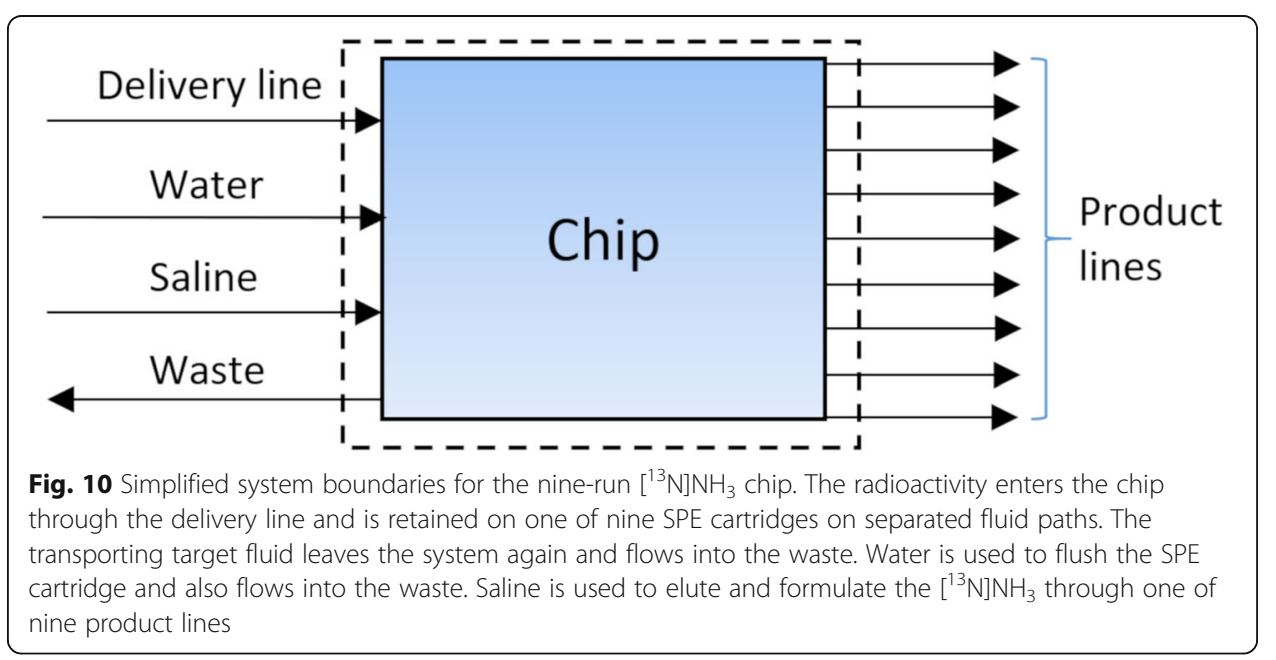


Real-time valve control enables gas-pressure driven fluid transport at accuracies historically only achievable by syringe pumps (Rensch et al. 2017).

ISAR is designed to perform complete radiosyntheses on chip, as recently demonstrated for $\left[{ }^{18} \mathrm{~F}\right] \mathrm{FDG}$ and $\left[{ }^{68} \mathrm{Ga}\right]$ PSMA-HBED-CC (see: Frank et al. 2018). As such, the ISAR chip includes two reaction chambers, and heating of these chambers is performed by four aluminum heating blocks. One above and below each reaction chamber. Active cooling capabilities are provided by blowing $\mathrm{N}_{2}$ gas through the heating blocks, enabling precise control and acceleration of cool-down ramps. Negative pressure can also be applied to the chip by duty cycle control of a vacuum pump, which can also be closed loop controlled, in combination with one of two installed pressure sensors, to a pre-set pressure value within any structure on the chip. Compared with traditional synthesizers, this allows a more precise application of vacuum, improving the overall process control, e.g. for azeotropic drying procedures on-chip as demonstrated for $\left[{ }^{18} \mathrm{~F}\right]$ FDG (Frank et al. 2018).

To facilitate gas pressure driven fluid transport, the $\mathrm{N}_{2}$ gas source needed for the clamping of the consumable and valve actuation is also further regulated by a mass flow controller, capable of controlling both flow (up to $1000 \mathrm{~mL} \cdot \mathrm{min}^{-1}$ ) and pressure (up to 2 bar). Combined with metering structures and the precise actuating of valves described, no syringe pumps are needed since fluids on the chip can be driven by overpressure. This allows highly efficient fluid recovery (Table 2), and helps to reduce the cost, size and technical complexity of an ISAR unit. In addition, the available functionality for fluid routing and control is increased beyond what is achievable by some of the largest ( $2 \mathrm{x}$ to $3 \mathrm{x}$ of ISAR unit size) stopcock valve and syringe pump-based synthesizers currently available.

\section{Radiosynthesis of $\left[{ }^{13} \mathrm{~N}^{\mathrm{N} H} \mathrm{H}_{3}\right.$}

To produce $\left[{ }^{13} \mathrm{~N}\right] \mathrm{NH}_{3}$, a custom chip layout was created utilizing the methods described. It enables nine back-to-back productions without the need to reopen a hot-cell (Fig. 8). Each production line on the chip is separated from one another, while still being fed by one delivery line and a single set of fluid-containers, e.g. water, saline, waste (Fig. 10). The chip combined with the ISAR unit acts as a conductor between everything entering and leaving the chip, while preventing cross contamination through

Table 2 Fluid recovery with ISAR

\begin{tabular}{|c|c|c|c|c|c|c|c|}
\hline \multirow[t]{3}{*}{ Liquid } & \multicolumn{3}{|c|}{ Target } & \multicolumn{3}{|c|}{ Achieved } & \multirow[t]{3}{*}{$\mathrm{n}$} \\
\hline & time & volume & accuracy & time & volume & Standard deviation & \\
\hline & $\min$ & $\mu \mathrm{L}$ & $\pm \mu \mathrm{L}$ & $\min$ & $\mu \mathrm{L}$ & $\pm \mu \mathrm{L}$ & \\
\hline \multirow[t]{3}{*}{$\mathrm{H}_{2} \mathrm{O}$} & 2 & 6000 & 200 & 3 & 6163 & 56 & 5 \\
\hline & 2 & 1500 & 200 & 4 & 1532 & 49 & 10 \\
\hline & 3 & 300 & 50 & 2 & 298 & 3 & 5 \\
\hline \multirow[t]{3}{*}{ EtOH } & 2 & 1500 & 200 & 4 & 1512 & 69 & 10 \\
\hline & 2 & 400 & 50 & 3 & 378 & 22 & 6 \\
\hline & 3 & 100 & 50 & 1 & 101 & 4 & 10 \\
\hline \multirow[t]{2}{*}{$\mathrm{MeCN}$} & 3 & 500 & 50 & 2 & 520 & 10 & 5 \\
\hline & 3 & 100 & 50 & 1 & 101 & 7 & 10 \\
\hline
\end{tabular}


downstream separation of each synthesis fluid path and maintenance of a single direction for fluid propagation. This is enabled by the chip architecture as described and is not feasible on conventional stopcock valve-based synthesizers.

$\left[{ }^{13} \mathrm{~N}\right] \mathrm{NH}_{3}$ was prepared in target on a GE PETtrace cyclotron by irradiating aqueous ethanol $(5 \mathrm{mM})$ at $40 \mu \mathrm{A}$ for $10-30 \mathrm{~min}$, according to a published method (Wieland et al. 1991). The resulting $\left[{ }^{13} \mathrm{~N}\right] \mathrm{NH}_{3}$ was then transferred to the ISAR unit through the delivery line. Subsequently it was trapped on one of 9 parallel Waters CM-Light SepPak cartridges connected to the ISAR chip (Fig. 8). The cartridge was rinsed with sterile water for injection, Ph. Eur. $(2 \mathrm{~mL})$, and afterwards $\left[{ }^{13} \mathrm{~N}\right] \mathrm{NH}_{3}$ was eluted from the cartridge using $0.9 \% \mathrm{NaCl}$, Ph. Eur. $(2 \mathrm{~mL})$, through a $0.22 \mu \mathrm{m}$ sterile filter (Millipore Millex GS) into a sterile dose vial (Hollister-Stier). QC testing was completed as previously described (Scott 2012). Processing of $\left[{ }^{13} \mathrm{~N}\right] \mathrm{NH}_{3}$ by ISAR took $5 \mathrm{~min}$ after end-ofbombardment.

\section{Rodent PET imaging with $\left[{ }^{13} \mathrm{~N}\right] \mathrm{NH}_{3}$}

Rodent PET imaging with $\left[{ }^{13} \mathrm{~N}\right] \mathrm{NH}_{3}$ was conducted in a female Sprague Dawley rat $(321 \mathrm{~g})$ in accordance with the standards set by the Institutional Animal Care and Use Committee at the University of Michigan. The animal was anesthetized (isoflurane), intubated, and positioned in a Concorde MicroPET P4 scanner. Following a transmission scan, the animal was injected (i.v. via tail vein catheter as a bolus over $1 \mathrm{~min}$ ) with $\left[{ }^{13} \mathrm{~N}\right] \mathrm{NH}_{3}(10 \mathrm{MBq})$ and the heart imaged for $30 \mathrm{~min}(6 \times 5 \mathrm{~min}$ frames $)$.

Emission data were corrected for attenuation/scatter and reconstructed using the 3D maximum a priori method. By using a summed image (Fig. 11), a region-of-interest was drawn over the heart on multiple planes, and the corresponding volume of interest applied to the full dynamic data set to generate a time-activity curve.

\section{Results and discussion}

The ISAR synthesis platform (Figs. 2 and 8) replaces the traditional stopcock valve manifolds found on state-of-the-art radiopharmaceutical synthesis modules by means
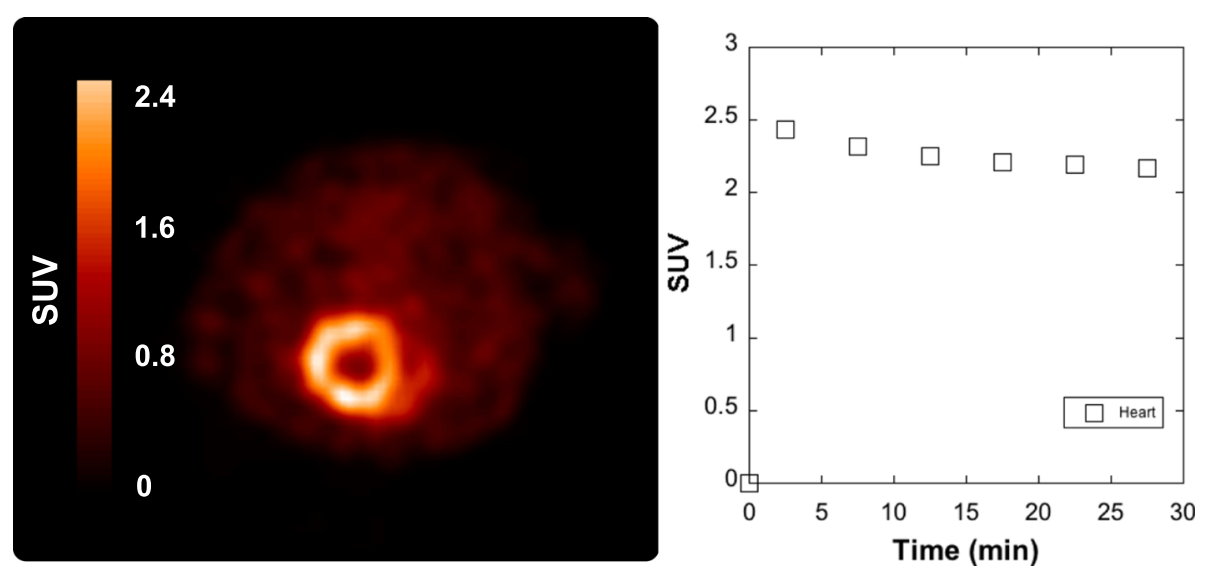

Fig. 11 Summed transverse rodent image of $\left[{ }^{13} \mathrm{~N}_{\mathrm{NH}}(0-30 \mathrm{~min}\right.$ after injection of the radiopharmaceutical) showing excellent visualization of the heart and good heart-to background contrast and associated time-radioactivity curve 
of a fluidic chip (Figs. 3 and 6) which integrates 70 membrane valves and fluid paths (tubing) as well as 2 reaction chambers into one consumable, enabling channel routing without traditional single fluid bus constraints. The chip can interface to SPE cartridges, different vial formats, sterile filters as well as inlet and outlet tubing employed in radiopharmaceutical syntheses, ensuring compatibility at the macro-to-micro interface. The prototype ISAR chips contain two reaction chambers as they were initially developed for complex tracer synthesis like $\left[{ }^{18} \mathrm{~F}\right] \mathrm{FDG}$ (Frank et al. 2018), and drying and recovery of fluorine-18 in a reproducible way is challenging using alternative microfluidic approaches such as flow reactors, especially when standard vials and SPE cartridges are used. We subsequently employed these prototype reactor-based chips to prepare $\left[{ }^{68} \mathrm{Ga}\right]$ PSMA (Frank et al. 2018).

In combination with real-time valve control that enables gas-pressure driven fluid transport at accuracies comparable to syringe pumps, ISAR combines the benefits of both worlds, by downsizing where it is beneficial (e.g. reduced precursor consumption), while maintaining established output volumes (e.g. 5-25 mL), purification techniques (SPE cartridges), and formulation methods. The flexibility offered by this technology enables parallel fluidic processing. We realized that parallel processing is also well suited for multi-run schemes of simple production processes (e.g. $\left[{ }^{13} \mathrm{~N}\right] \mathrm{NH}_{3}$ ), without reuse of contaminated structures and complex cleaning validation (Haka et al. 2017). While such could be possibly be accomplished with homemade valve manifolds, we are unaware of any system capable of handling enough manifolds to offer 9 production lines that are completely separate from each other and enable cGMP synthesis of multiple batches of $\left[{ }^{13} \mathrm{~N}_{\mathrm{NH}_{3}}\right.$. Moreover, homemade systems are usually controlled by syringe pumps, and not readily fed by single inputs for cyclotron target/water/saline input, meaning footprints can be significantly larger. Contrastingly, ISAR is very compact, uses a single set of reagents for 9 syntheses, and the speed of actuation is higher such that there is no need for syringe pumps. As such, multiple ISAR units can easily be installed in a single min-cell or hot-cell. The flexibility in chip design is an additional advantage of ISAR. Small numbers of new chips can be rapidly accessed for evaluation via rapid prototyping by, for example, 3D printing or milling (Fig. 7). This allows faster implementation of established and new synthesis processes compared with stopcock valve architectures, since the radiosynthesis no longer needs to be customized for the consumable; instead the consumable can now be customized for the process.

With prototype systems built, it was next demonstrated that the ISAR system can be installed at an academic PET Center and used for manufacturing of high quality $\left[{ }^{13} \mathrm{~N}\right] \mathrm{NH}_{3}$. Installation was quick and simple $(<1 \mathrm{~h})$ and 9 back-to-back batches of $\left[{ }^{13} \mathrm{~N}\right] \mathrm{NH}_{3}$ were immediately produced without reopening the hot-cell or changing any consumables (Table 3, entry 1). Additional runs with the same parameters were performed (Table 3, entry 2) and confirmed that $\left[{ }^{13} \mathrm{~N}\right] \mathrm{NH}_{3}$ was obtained at $>96 \%$ radiochemical yield based on the input activity. To confirm suitability of $\left[{ }^{13} \mathrm{~N}\right] \mathrm{NH}_{3}$ prepared on ISAR for clinical use, three additional sub-batches were prepared, and full QC testing was completed (Table 3, entry 3; Table 4). All doses met or exceeded release criteria for clinical application at the University of Michigan, including purity and sterility. Yields were significantly higher than our existing method for producing $\left[{ }^{13} \mathrm{~N}^{2} \mathrm{NH}_{3}\right.$ using Devarda's alloy (Table 3, entry 4), even accounting for differences in cyclotron parameters (Scott 2012). Moreover, the ability to make 9 sub-batches of $\left[{ }^{13} \mathrm{~N}\right] \mathrm{NH}_{3}$ from 
Table 3 Activity yield of the $\left[{ }^{13} \mathrm{~N} \mathrm{NH}_{3}\right.$ Radiosyntheses

\begin{tabular}{|c|c|c|c|}
\hline Entry & Beam & Activity Yield (GBq) & $n$ \\
\hline 1 & $40 \mu \mathrm{A}$ for $10 \mathrm{~min}$ & $7.0 \pm 2.0$ & 9 \\
\hline 2 & $40 \mu \mathrm{A}$ for $10 \mathrm{~min}$ & $8.9 \pm 0.3$ & 8 \\
\hline $3^{a}$ & $40 \mu \mathrm{A}$ for $10 \mathrm{~min}$ & $8.5 \pm 0.7$ & 3 \\
\hline $4^{b}$ & $30 \mu \mathrm{A}$ for $6 \mathrm{~min}$ & $2.5 \pm 0.2$ & 3 \\
\hline $5^{c}$ & $40 \mu \mathrm{A}$ for $10 \mathrm{~min}$ & $8.8 \pm 0.1$ & 3 \\
\hline $6^{d}$ & $40 \mu \mathrm{A}$ for $30 \mathrm{~min}$ & $23.7 \pm 0.9$ & 2 \\
\hline
\end{tabular}

a single consumable, compared with the existing Devarda's alloy method that requires replacement of consumables and reagents for every sub-batch (Scott 2012), improves our throughput and streamlines daily production of $\left[{ }^{13} \mathrm{~N}^{-N_{3}}\right.$ for imaging multiple patients. These improvements in both yield and throughput represent dramatic enhancements to the radiopharmaceutical process resulting from installation of ISAR at the University of Michigan.

Although we only anticipate using a chip once for clinical production for the reasons described above, we were next curious from a reliability perspective whether chips could be re-used. Therefore, we investigated whether each fluid path, line and CM cartridge could be used again by rinsing the three channels employed for making the original QC batches (Table 3, entry 3) with $10 \mathrm{~mL}$ of sterile water for injection, Ph. Eur. Rinsing was automated and performed without opening the hot-cell. Three additional syntheses of $\left[{ }^{13} \mathrm{~N}\right] \mathrm{NH}_{3}$ were then performed using the same channels. There was no impact on activity yield (Table 3, entry 5 ) and QC testing confirmed that these consecutive batches also met or exceeded all the necessary release criteria (data not shown). Lastly, the ISAR system was also tested with higher levels of activity. The irradiation time was increased to $30 \mathrm{~min}$ at $40 \mu \mathrm{A}$, and the resulting activity was purified and formulated without any anomalies to generate over $20 \mathrm{GBq}$ of $\left[{ }^{13} \mathrm{~N}\right] \mathrm{NH}_{3}($ Table 3, entry 6).

In a final demonstration of the suitability of ISAR to produce radiopharmaceuticals for in vivo PET imaging, the heart of a Sprague-Dawley rat was imaged with $\left[{ }^{13} \mathrm{~N}^{-N_{3}}\right.$ manufactured using ISAR (Fig. 11). The PET image demonstrated excellent visualization of the heart and good heart-to-background contrast. A region-of-interest

Table 4 QC Data for $\left[{ }^{13} \mathrm{~N} \mathrm{NH}_{3}\right.$ validation runs. All doses met or exceeded release criteria for clinical application at the University of Michigan

\begin{tabular}{lllll}
\hline QC Tests & Specifications & Lot 1 & Lot 2 & Lot 3 \\
\hline Visual Inspection & Clear, colorless, no ppt & Pass & Pass & Pass \\
Radiochemical-ID & RRT $^{\text {a }}$ 0.9-1.1 & 0.94 & 0.95 & 0.97 \\
Radionuclidic-ID & $\mathrm{t}_{1 / 2}: 9.5-10.5 \mathrm{~min}$ & 9.99 & 9.97 & 10.00 \\
Filter integrity & Bubble point $\geq 50$ psi & 53 & 61 & 62 \\
Endotoxins & $\leq 43.75 \mathrm{EU} / \mathrm{mL}$ & $<2.00$ & $<2.00$ & $<2.00$ \\
Sterility & No microbial growth & Pass & Pass & Pass \\
pH value & $4.5-7.5$ & 5.0 & 5.0 & 5.0 \\
RCP & $\geq 90 \%$ & $>99.9 \%$ & $>99.9 \%$ & $>99.9 \%$ \\
\hline
\end{tabular}

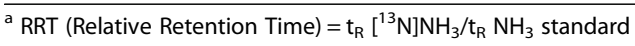


was established for the heart and used to generate the associated time-activity curve, which was consistent with previous reports in the literature (Kim et al. 2015). Obtaining the necessary U.S. regulatory approval to use $\left[{ }^{13} \mathrm{~N}\right] \mathrm{NH}_{3}$ manufactured with ISAR in a clinical setting is underway.

\section{Conclusion}

ISAR represents a potential new paradigm in radiopharmaceutical production capitalizing on decades of synthesizer technology development. Through a new system architecture, ISAR integrates the principles of microfluidics with the standard volumes and consumables established in PET Centers all over the world. A parallel fluidic strategy offers a promising approach for the automated production of radiopharmaceuticals and has been demonstrated for $\left[{ }^{13} \mathrm{~N}\right] \mathrm{NH}_{3}$, leveraging the ability to create multiple separated fluid paths on a single chip to its full potential. Validation of ISAR for production of other PET radiopharmaceuticals is ongoing. Straightforward compliance with cGMP is possible because of the consumable approach, since the ISAR chips interface with established reagent kits and SPE cartridges, as well as existing aseptic techniques.

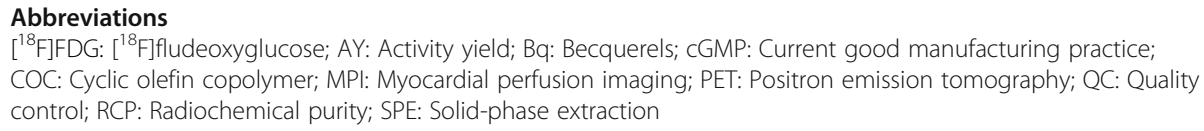

\section{Acknowledgments}

The authors thank Janna Arteaga, Jenelle Stauff and Phillip Sherman for assistance with the rodent PET scan, and all project members involved during ISAR development at former GE Global Research (Munich, Germany).

\section{Authors' contributions}

CF, GW, CR and PJHS conceived and designed experiments; CF, GW, FR, VS, CR designed and assembled ISAR; GW, AFB and $\mathrm{BDH}$ conducted $\left[^{13} \mathrm{~N}_{\mathrm{NH}_{3}}\right.$ manufacturing and quality control testing; $\mathrm{BDH}$ and $\mathrm{BGH}$ provided quality assurance and regulatory oversight; AFB and PJHS analyzed PET images; all authors analyzed data and wrote the manuscript. All authors read and approved the final manuscript.

\section{Funding}

Financial support from the Bundesministerium für Bildung und Forschung (German Federal Ministry of Education and Research) is gratefully acknowledged.

\section{Availability of data and materials on reasonable request. \\ Ethics approval and consent to participate \\ Not applicable. \\ Consent for publication \\ Not applicable. \\ Competing interests \\ CF, GW, FR, VS, and CR are employees of General Electric.}

The datasets generated during and/or analyzed during the current study are available from the corresponding author

\section{Author details}

${ }^{1}$ GE Healthcare, Oskar-Schlemmer-Str. 11, 80807 Munich, Germany. ${ }^{2}$ GE Healthcare, Uppsala, Sweden. ${ }^{3}$ GE Additive, Garching near Munich, Germany. ${ }^{4}$ Department of Radiology, University of Michigan, 2276 Medical Science Bldg I, SPC 5610, Ann Arbor, MI 48109, USA.

Received: 18 July 2019 Accepted: 30 August 2019

Published online: 18 September 2019

\section{References}

Amaraesekera B, Marchis PD, Bobinski KP, Radu CG, Czernin J, Barrio JR, van Dam RM. High-pressure, compact, modular radiosynthesizer for production of positron emitting biomarkers. Appl Radiat Isot. 2013;78:88-101.

Ametamey SM, Honer M, Schubiger PA. Molecular imaging with PET. Chem Rev. 2008;108:1501-16.

Attia UM, Marson S, Alcock JR. Micro-injection moulding of polymer microfluidic devices. Microfluid Nanofluid. 2009;7:1-28. 
Audrain H. Positron emission tomography (PET) and microfluidic devices: a breakthrough on the microscale? Angew Chem Int Ed. 2007:46:1772-5.

Awasthi V, Watson J, Gali H, Matlock G, McFarland A, Bailey J, Anzellotti A. A "dose on demand" biomarker generator for automated production of $\left[{ }^{18} \mathrm{~F}\right] \mathrm{F}^{-}$and $\left[{ }^{18} \mathrm{~F}\right] \mathrm{FDG}$. Appl Radiat Isot. 2014;89:167-75.

Bejot R, Kersemans V, Kelly C, Carroll L, King RC, Gouverneur V, Elizarov AM, Ball C, Zhang J, Miraghaie R, Kolb HC, Smart S, Hill S. Pre-clinical evaluation of a 3-nitro-1,2,4-triazole analogue of $\left[{ }^{18} \mathrm{~F}\right] \mathrm{FMISO}$ as hypoxia-selective tracer for PET. Nucl Med Biol. 2010;37:565-75.

Bouvet V, Wuest M, Tam PH, Wang M, Wuest F. Microfluidic technology: an economical and versatile approach for the synthesis of O-(2-[18 F]fluoroethyl)-L-tyrosine ([18 F]FET). Bioorg Med Chem Lett. 2012;22:2291-5.

Bouvet VR, Wuest F. Application of $\left.{ }^{18} \mathrm{~F}\right]$ FDG in radiolabeling reactions using microfluidic technology. Lab Chip. 2013;13: 4290-4.

Bouvet VR, Wuest M, Wiebe LI, Wuest F. Synthesis of hypoxia imaging agent 1-(5-deoxy-5-fluoro-a-D-arabinofuranosyl)-2nitroimidazole using microfluidic technology. Nucl Med Biol. 2011;38:235-45.

Chao PH, Collins J, Argus JP, Tseng W-Y, Lee JT, van Dam RM. Automatic concentration and reformulation of PET tracers via microfluidic membrane distillation. Lab Chip. 2017;17:1802-16.

Chen S, Javed MR, Kim HK, Lei J, Lazari M, Shah GJ, van Dam RM, Keng PY, Kim CJ. Radiolabelling diverse positron emission tomography (PET) tracers using a single digital microfluidic reactor chip. Lab Chip. 2014;14:902-10.

Chiu DT, DeMello AJ, Carlo DD, Doyle PS, Hansen C, Maceiczyk RM, Wootton RCR. Small but perfectly formed? Successes, challenges, and opportunities for microfluidics in the chemical and biological cciences. Chem. 2017;2:201-23.

Collier T, Akula M, Kabalka G. Microfluidic synthesis of [18 F] FMISO. J Nucl Med. 2010;51(Suppl. 2):1462.

Collier TL, Liang SH, Mann JJ, Vasdev N, Kumar JSD. Microfluidic radiosynthesis of $\left[{ }^{18} \mathrm{~F}\right]$ FEMPT, a high affinity PET radiotracer for imaging serotonin receptors. Beilstein J Org Chem. 2017;13:2922-7.

De Leonardis F, Pascali G, Salvadori PA, Watts P, Pamme N. Microfluidic modules for $\left[{ }^{18} \mathrm{~F}^{-}\right]$activation - towards an integrated modular lab on a chip for PET radiotracer synthesis. Proc MicroTAS. 2010:1604-6.

De Leonardis F, Pascali G, Salvadori PA, Watts P, Pamme N. On-chip pre-concentration and complexation of $\left[^{18} \mathrm{~F}\right]$ fluoride ions via regenerable anion exchange particles for radiochemical synthesis of positron emission tomography tracers. J Chromatogr A. 2011;1218:4714-9.

Elizarov AM. Microreactors for radiopharmaceutical synthesis. Lab Chip. 2009;9:1326-33.

Elizarov AM, van Dam RM, Shin YS, Kolb HC, Padgett HC, Stout D, Shu J, Huang J, Daridon A, Heath JR. Design and optimization of coin-shaped microreactor chips for PET radiopharmaceutical synthesis. J Nucl Med. 2010;51:282-7.

Elsinga PH. Present and future of PET radiopharmaceuticals. Nucl Med Rev. 2012;15:C13-6.

Fortt R, Gee A. Microfluidics: a golden opportunity for positron emission tomography? Future Med Chem. 2013;5:241-4.

Frank C, Winter G, Rensei F, Sampler V, Bartenstein P, Brooks A, Hockley B, Henderson B, Lindner S, Rensch C, Scott P. Enhancing radiotracer development: channel routing on ISAR without single fluid bus constraint. J Nucl Med. 2018; 59(Suppl. 1):671.

Gaja V, Gómez-Vallejo V, Cuadrado-Tejedor M, Borrell Il, Llop J. Synthesis of ${ }^{13} \mathrm{~N}$-labelled radiotracers by using microfluidic technology. J Label Compd Radiopharm. 2012;55:332-8.

Gillies JM, Prenant C, Chimon GN, Smethurst GJ, Perrie W, Hamblett I, Dekker B, Zweit J. Microfluidic reactor for the radiosynthesis of PET radiotracers. Appl Radiat Isot. 2006;64:325-32.

Guckenberger DJ, de Groot TE, Wan AMD, Beebe DJ, Young EWK. Micromilling: a method for ultra-rapid prototyping of plastic microfluidic devices. Lab Chip. 2015;15:2364-78.

Ha NS, Sadeghi S, Van Dam RN. Recent progress toward microfluidic quality control testing of radiopharmaceuticals. Micromachines. 2017;8:337.

Haka M, Walsh J, Webster E. P450: cleaning validation concepts for commercial radiopharmaceutical manufacturing. J Label Compd Radiopharm. 2017;60(Suppl 1):S632.

Kealey S, Plisson C, Collier TL, Long NJ, Husbands SM, Martarello L, Gee AD. Microfluidic reactions using $\left[{ }^{11} \mathrm{C}\right]$ carbon monoxide solutions for the synthesis of a positron emission tomography radiotracer. Org Biomol Chem. 2011;9:3313-9.

Keng PY, Chen S, Ding H, Sadeghi S, Shah GJ, Dooraghi A, Phelps ME, Satyamurthy N, Chatziioannou AF, Kim CJ, van Dam RM. Micro-chemical synthesis of molecular probes on an electronic microfluidic device. Proc Natl Acad Sci U S A. 2012b; 109:690-5.

Keng PY, Esterby M, van Dam RM. Emerging technologies for decentralized production of PET tracers. In: Hsieh C-H, editor. Positron Emission Tomography - Current Clinical and Research Applications. Rijeka: InTech; 2012a, Ch. 6. p. 153-82.

Keng PY, van Dam RM. Digital microfluidics: a new paradigm for radiochemistry. Mol Imaging. 2015;14:13-4.

Kim DY, Kim HS, Reder S, Zheng JH, Herz M, Higuchi T, Pyo AY, Bom HS, Schwaiger M, Min JJ. Comparison of ${ }^{18}$ F-labeled fluoroalkylphosphonium cations with ${ }^{13} \mathrm{~N}^{-\mathrm{NH}_{3}}$ for PET myocardial perfusion imaging. J Nucl Med. 2015;56:1581-6.

Lebedev A, Miraghaie R, Kotta K, Ball CE, Zhang J, Buchsbaum MS, Kolb HC, Elizarov A. Batch-reactor microfluidic device: first human use of a microfluidically produced PET radiotracer. Lab Chip. 2013;13:136-45.

Lee CC, Sui G, Elizarov A, Shu CJ, Shin YS, Dooley AN, Huang J, Daridon A, Wyatt P, Stout D, Kolb HC, Witte ON, Satyamurthy $\mathrm{N}$, Heath JR, Phelps ME, Quake SR, Tseng HR. Multistep synthesis of a radiolabeled imaging probe using integrated microfluidics. Science. 2005;310:1793-6.

Liang SH, Yokell DL, Jackson RN, Rice PA, Callahan R, Johnson KA, Alagille D, Tamagnan G, Collier TL, Vasdev N. Microfluidic continuous-flow radiosynthesis of $\left[{ }^{18} \mathrm{~F}\right]$ FPEB suitable for human PET imaging. Med Chem Commun. 2014a;5:432-5.

Liang SH, Yokell DL, Normandin MD, Rice PA, Jackson RN, Shoup TM, Brady TJ, El Fakhri G, Collier TL, Vasdev N. First human use of a radiopharmaceutical prepared by continuous-flow microfluidic radiofluorination: proof of concept with the tau imaging agent $\left[{ }^{18} \mathrm{~F}\right] \mathrm{T} 807$. Mol Imaging. 2014b;13. https://doi.org/10.2310/7290.2014.00025.

Liow E, O'Brien A, Luthra S, Brady F, Steel C. Preliminary studies of conducting high level production radiosyntheses using microfluidic devices. J Label Compd Radiopharm. 2005;48:28.

Liu K, Lepin EJ, Wang MW, Guo F, Lin WY, Chen YC, Sirk SJ, Olma S, Phelps ME, Zhao XZ, Tseng HR, Michael van Dam R, Wu AM, Shen CK. Microfluidic-based ${ }^{18}$ F-labeling of biomolecules for immuno-positron emission tomography. Mol Imaging. 2011;10:168-76 
Liu Y, Tian M, Zhang H. Microfluidics for synthesis of peptide-based PET tracers. Biomed Res Int. 2013;2013, 839683.

Lu S, Chun JH, Pike WW. Fluorine-18 chemistry in micro-reactors. J Labelled Comp Radiopharm. 2010;53:234-8.

Lu S, Giamis AM, Pike WW. Synthesis of $\left[{ }^{18} \mathrm{~F}\right]$ fallypride in a micro-reactor: rapid optimization and multiple-production in small doses for micro-PET studies. Curr Radiopharm. 2009;2:49-55.

Lu S, Pike WW. Synthesis of $\left[{ }^{18} \mathrm{~F}\right]$ xenon difluoride as a radiolabeling reagent from $\left[{ }^{18} \mathrm{~F}\right]$ fluoride ion in a micro-reactor and at production scale. J Fluor Chem. 2010;131:1032-8.

Lu SY, Pike WW. Micro-reactors for PET tracer labeling. Ernst Schering Res Found Workshop. 2007;62(PET Chemistry):271-87.

Lu SY, Watts P, Chin FT, Hong J, Musachio JL, Briard E, Pike WW. Syntheses of ${ }^{11} \mathrm{C}$ - and ${ }^{18} \mathrm{~F}$-labeled carboxylic esters within a hydrodynamically-driven micro-reactor. Lab Chip. 2004;4:523-5.

Ly J, Ha NS, Cheung S, van Dam RM. Toward miniaturized analysis of chemical identity and purity of radiopharmaceuticals via microchip electrophoresis. Anal Bioanal Chem. 2018:410:2423-36.

Matesic L, Kallinen A, Greguric I, Pascali G. Dose-on-demand production of diverse ${ }^{18} \mathrm{~F}$-radiotracers for preclinical applications using a continuous flow microfluidic system. Nucl Med Biol. 2017;52:24-31.

Miller PW. Radiolabelling with short-lived PET (positron emission tomography) isotopes using microfluidic reactors. J Chem Technol Biotechnol. 2009:84:309-15.

Miller PW, Audrain H, Bender D, deMello AJ, Gee AD, Long NJ, Vilar R. Rapid carbon-11 radiolabelling for PET using microfluidics. Chem A Eur J. 2011:17:460-3.

Miller PW, de Mello AJ, Gee AD. Application of microfluidics to the ultra-rapid preparation of fluorine-18 labelled compounds. Curr Radiopharm. 2010;3:254-62.

Murthy VL, Leuschner M, Scott PJH, Doughty M, Weinberg RL, Ficaro EP, Corbett JR. Abstracts of original contributions ASNC2016. Abstract 302-05: initial validation of a highly automated superconducting mini-cyclotron for decentralized production of ${ }^{13} \mathrm{~N}$-ammonia. J Nucl Cardiol. 2016;23:899-937.

Nakazato R, Berman DS, Alexanderson E, Slomka P. Myocardial perfusion imaging with PET. Imaging Med. 2013;5:35-46.

Pascali G, Berton A, DeSimone M, Wyatt N, Matesic L, Greguric I, Salvadori PA. Hardware and software modifications on the Advion NanoTek microfluidic platform to extend flexibility for radiochemical synthesis. Appl Radiat Isot. 2014;84:40-7.

Pascali G, Mazzone G, Saccomanni G, Manera C, Salvadori PA. Microfluidic approach for fast labeling optimization and doseon-demand implementation. Nucl Med Biol. 2010;37:547-55.

Pascali G, Nannavecchia G, Pitzianti S, Salvadori PA. Dose-on-demand of diverse ${ }^{18} \mathrm{~F}$-fluorocholine derivatives through a twostep microfluidic approach. Nucl Med Biol. 2011;38:637-44.

Pascali G, Salvadori PA. Opportunities and challenges in the utilization of microfluidic technologies to the production of radiopharmaceuticals. Chim Oggi Chem Today. 2016;34:28-32.

Pascali G, Watts P, Salvadori PA. Microfluidics in radiopharmaceutical chemistry. Nucl Med Biol. 2013:40:776-87.

PET Imaging Market Summary Report 2018. Available from: https://imvinfo.com/product/pet-imaging-market-summaryreport-2018/; Accessed 4 July 2019.

<823> Positron Emission Tomography Drugs for Compounding, Investigational, and Research Uses, in United States Pharmacopeia / National Formulary (USP 42-NF 37), The United States Pharmacopeia Convention, Rockville, 2018, Ch. 823 pp 322-331.

Rensch C, Jackson A, Lindner S, Salvamoser R, Samper V, Riese S, Bartenstein P, Wängler C, Wängler B. Microfluidics: a groundbreaking technology for PET tracer production? Molecules. 2013;18:7930-56.

Rensch C, Lindner S, Salvamoser R, Leidner S, Böld C, Samper V, Taylor D, Baller M, Riese S, Bartenstein P, Wängler C, Wängler B. A solvent resistant lab-on-chip platform for radiochemistry applications. Lab Chip. 2014;14:2556-64.

Rensch C, Salvamoser R, Lang P, Samper V, Winter G, Frank C, Hienzsch A, Hesse R, Müller M, Hoepping A. Gas pressure driven fluid transport for radiochemistry on-chip. J Label Compd Radiopharm. 2017:60(Suppl. 1):0 064.

Rensch C, Samper V, Salvamoser R. Compact valve array with actuation system. US Pat. 2018;20180078937:A1.

Rensch C, Waengler B, Yaroshenko A, Samper V, Baller M, Heumesser N, Ulin J, Riese S, Reischl G. Microfluidic reactor geometries for radiolysis reduction in radiopharmaceuticals. Appl Radiat Isot. 2012;70:1691-7.

Scott PJH. Synthesis of $\left[\left[^{13} \mathrm{~N}\right]\right.$ Ammonia $\left(\left[^{13} \mathrm{~N}^{\mathrm{N} \mathrm{NH}_{3}}\right)\right.$. In: PJH S, Hockley BG, editors. Radiochemical Syntheses Volume 1: Radiopharmaceuticals for PET Imaging. Hoboken: Wiley; 2012;Ch. 31. p. 315-20.

Selivanova SV, Mu L, Ungersboeck J, Stellfeld T, Ametamey SM, Schibli R, Wadsak W. Single-step radiofluorination of peptides using continuous flow microreactor. Org Biomol Chem. 2012;10:3871-4.

Simms RW, Causey PW, Weaver DM, Sundararajan C, Stephenson KA, Valliant JF. Preparation of technetium-99m bifunctional chelate complexes using a microfluidic reactor: a comparative study with conventional and microwave labeling methods. J Label Compd Radiopharm. 2012;55:18-22.

Steel CJ, O'Brien AT, Luthra SK, Brady F. Automated PET radiosyntheses using microfluidic devices. J Label Compd Radiopharm. 2007;50:308-11.

Taggart MP, Tarn MD, Esfahani MM, Schofield DM, Brown NJ, Archibald SJ, Deakin T, Pamme N, Thompson LF. Development of radiodetection systems towards miniaturised quality control of PET and SPECT radiopharmaceuticals. Lab Chip. 2016; 16:1605-16.

Thompson S, Scott PJH. Equipment and instrumentation for radiopharmaceutical chemistry. In: Lewis JS, Windhorst AD, Zeglis BM, editors. Radiopharmaceutical Chemistry. New York: Springer; 2019. p. 481-99.

Ungersboeck J, Philippe C, Haeusler D, Mitterhauser M, Lanzenberger R, Dudczak R, Wadsak W. Optimization of [ $\left.{ }^{11} \mathrm{C}\right] \mathrm{DASB}-$ synthesis: vessel-based and flow-through microreactor methods. Appl Radiat Isot. 2012a;70:2615-20.

Ungersboeck J, Philippe C, Mien LK, Haeusler D, Shanab K, Lanzenberger R, Spreitzer H, Keppler BK, Dudczak R, Kletter K, Mitterhauser M, Wadsak W. Microfluidic preparation of [ $\left.{ }^{18} \mathrm{~F}\right] \mathrm{FE} @ S U P P Y$ and $\left[{ }^{18} \mathrm{~F}\right] \mathrm{FE} @ S U P P Y: 2-$-comparison with conventional radiosyntheses. Nucl Med Biol. 2011;38:427-34.

Ungersboeck J, Richter S, Collier L, Mitterhauser M, Karanikas G, Lanzenberger R, Dudczak R, Wadsak W. Radiolabeling of $\left[{ }^{18} \mathrm{~F}\right]$ altanserin - a microfluidic approach. Nucl Med Biol. 2012b;39:1087-92.

Vavere AL, Scott PJH. Clinical applications of small-molecule PET radiotracers: Current progress and future outlook. Semin Nucl Med. 2017:47:429-53.

Voccia S, Morelle JL, Aerts J, Lemaire C, Luxen A, Phillipart G. Mini-fluidic chip for the total synthesis of PET tracers. J Labe Compd Radiopharm. 2009;52(Suppl):S11. 
Wang J, Chao PH, van Dam RM. Ultra-compact, automated microdroplet radiosynthesizer. Lab Chip. 2019. https://doi.org/10. 1039/c9lc00438f.

Wang M-W, Lin W-Y, Liu K, Masterman-Smith M, Shen CK-F. Microfluidics for positron emission tomography (PET) imaging probe development. Mol Imaging. 2010;9:175-91.

Wester HJ, Schoultz BW, Hultsch C, Henriksen G. Fast and repetitive in-capillary production of [ $\left.{ }^{18} \mathrm{~F}\right] \mathrm{FDG}$. Eur J Nucl Med Mol Imaging. 2009;36:653-8.

Wheeler TD, Zeng D, Desai AV, Önal B, Reichert DE, Kenis PJ. Microfluidic labeling of biomolecules with radiometals for use in nuclear medicine. Lab Chip. 2010;10:3387-96.

Wieland B, Bida G, Padgett H, Hendry G, Zippi E, Kabalka G, Morelle J-L, Verbruggen R, Ghyoot M. In target production of ${ }^{13} \mathrm{~N}$ ammonia via proton irradiation of aqueous ethanol and acetic acid mixtures. Appl Radiat Isot. 1991;42:1095-8.

Yokell DL, Leece AK, Lebedev A, Miraghaie R, Ball CE, Zhang J, Kolb H, Elizarov A, Mahmood U. Microfluidic single vessel production of hypoxia tracer $1 \mathrm{H}-1$ - $\left(3-\left[{ }^{18} \mathrm{~F}\right]\right.$-fluoro-2-hydroxy-propyl)-2-nitro-imidazole ([ $\left.\left.{ }^{18} \mathrm{~F}\right]-\mathrm{FMISO}\right)$. Appl Radiat Isot. 2012; 70:2313-6.

Yoshinaga K, Klein R, Tamaki N. Generator-produced rubidium-82 positron emission tomography myocardial perfusion imaging: from basic aspects to clinical applications. J Cardiol. 2010;55:163-73.

Yu S. Review of ${ }^{18} \mathrm{~F}-\mathrm{FDG}$ synthesis and quality control. Biomed Imaging Interv J. 2006;2:e57.

Zeng D, Desai AV, Ranganathan D, Wheeler TD, Kenis PJ, Reichert DE. Microfluidic radiolabeling of biomolecules with PET radiometals. Nucl Med Biol. 2013;40:42-51.

\section{Publisher's Note}

Springer Nature remains neutral with regard to jurisdictional claims in published maps and institutional affiliations.

Submit your manuscript to a SpringerOpen ${ }^{\circ}$ journal and benefit from:

- Convenient online submission

- Rigorous peer review

- Open access: articles freely available online

High visibility within the field

- Retaining the copyright to your article

Submit your next manuscript at $\boldsymbol{\nabla}$ springeropen.com 